\title{
Brain Hyperthermia Is Induced by Methamphetamine and Exacerbated by Social Interaction
}

\author{
P. Leon Brown, Roy A. Wise, and Eugene A. Kiyatkin \\ Behavioral Neuroscience Branch, National Institute on Drug Abuse, Intramural Research Program, Baltimore, Maryland 21224
}

\begin{abstract}
Hyperthermia is a symptom of methamphetamine (METH) intoxication and a factor implicated in neurotoxicity during chronic METH use. To characterize the thermic response to METH, it was injected once daily into rats at increasing doses $(0,1,3$, and $9 \mathrm{mg} / \mathrm{kg}$, s.c.) while brain [nucleus accumbens (NAcc), hippocampus] and body (deep temporal muscle) temperatures were continuously monitored. METH produced dose-dependent hyperthermia, with brain structures (especially the NAcc) showing a more rapid and pronounced temperature increase than the muscle. At the highest dose, brain and body temperatures increased $3.5-4.0^{\circ} \mathrm{C}$ above basal levels and remained elevated for 3-5 hr. Stressful and other high-activity situations such as interaction with a conspecific female are also known to induce a significant hyperthermic response in the rat. A combination of social interaction and METH administration was tested for additive effects. Male rats were exposed daily to a conspecific female for a total of $120 \mathrm{~min}$, and METH was injected at the same doses $30 \mathrm{~min}$ after the initial contact with the female. An initial hyperthermic response $\left(\sim 1.5^{\circ} \mathrm{C}\right)$ to social interaction was followed by a large and prolonged hyperthermic response $\left(3.5-5.0^{\circ} \mathrm{C}, 5-7 \mathrm{hr}\right.$ at $\left.9 \mathrm{mg} / \mathrm{kg}\right)$ to $\mathrm{METH}$, which was again stronger in brain structures (especially in the NAcc) than in the muscle. Although the combined effect of the hyperthermic events was not additive, METH administration during social interaction produced stronger and longer-lasting increases in brain and body temperature than that induced by drug alone, heating the brain in some animals near its biological limit $\left(>41^{\circ} \mathrm{C}\right)$.
\end{abstract}

Key words: brain temperature; hyperthermia; metabolic neural activation; nucleus accumbens; hippocampus; social interaction

\section{Introduction}

Methamphetamine (METH) and related compounds [amphetamine, paramethoxyamphetamine, and methylenedioxymethamphetamine ("ecstasy")] are addictive substances that can cause serious health problems ranging from acute overdose toxicity and mortality to brain damage with chronic use (Davidson et al., 2001; Kalant, 2001; Rawson et al., 2002). Because METH induces abnormal release of various endogenous transmitters, including glutamate and catecholamines (Stephens and Yamamoto, 1994; Ohmori et al., 1996; Seiden and Sabol, 1996), these substances and some toxic products of their metabolism (i.e., nitric oxide, catechol-quinones, peroxynitrite, and arachidonic acid) are usually considered primary contributors to neural cell damage via oxidative stress (Spina and Cohen, 1989; Lipton and Rosenberg, 1994; Kuhn and Geddes, 2000; Cadet et al., 2001). METH is also known to cause hyperthermia both in humans (Kalant and Kalant, 1975) and rodents (Sandoval et al., 2000), which appears to contribute to METH-induced neurotoxicity and mortality. Hyperthermia potentiates dopamine and tyrosine-hydroxylase depletion and astrocytosis and also exacerbates oxidative stress (Omar et al., 1987; Lin et al., 1991), whereas hypothermia protects against these effects (Bowyer et al., 1993, 1994; Miller and O'Callaghan, 1994).

Although the pattern of body hyperthermia after METH administration is well known (Sandoval et al., 2000), the associated changes in brain temperature and the relationship between brain

Received Dec. 3, 2002; revised Jan. 29, 2003; accepted Feb. 11, 2003.

Correspondence should be addressed to Eugene A. Kiyatkin at the above address. E-mail: ekiyatki@intra.nida.nih.gov.

Copyright $\odot 2003$ Society for Neuroscience $\quad$ 0270-6474/03/233924-06\$15.00/0 and body hyperthermia have not been thoroughly examined. We examined the pattern of changes in brain and body temperature after systemic administration of METH at various doses in rats. Recordings were simultaneously made in the ventral striatum [the shell of the nucleus accumbens (NAcc)], hippocampus, and deep temporal muscle (musculus temporalis). The NAcc and hippocampus were chosen as brain structures that have, respectively, relatively high and low basal temperatures and that show different responses to environmental challenges (Kiyatkin et al., 2002). Temporal muscle was chosen because it is a nonlocomotor head muscle that has a blood supply similar to that of the brain.

Because brain and body hyperthermia are also induced by various stressful and arousing situations, such as interaction with conspecifics (Kiyatkin et al., 2002), and because psychostimulant drugs are often consumed by humans in social situations (for review, see Kalant, 2001), our evaluations of brain and body temperature were made under both quiet resting conditions and during social interaction with a nonreceptive female rat. Our previous work has shown that social interaction with conspecifics can elevate brain and body temperature by $1-2^{\circ} \mathrm{C}$ in the rat (Kiyatkin et al., 2002). Thus, the primary goals of the study were twofold: (1) to determine the relative changes in brain and body temperature induced by METH and (2) to determine the interaction between METH-induced and arousal-related hyperthermia.

\section{Materials and Methods}

Animals and surgery. Twelve male Long-Evans rats, weighing between 400 and 500 gm (Charles River Laboratories, Greensboro, NC), were used. Each rat was housed individually (12 hr light cycle beginning at 7:00 A.M.) with ad libitum access to food and water. Protocols were performed in compliance with the National Institutes of Health Guide for the Care and Use of Laboratory Animals (publication 865-23) and were ap- 
proved by the Animal Care and Use Committee of the National Institute on Drug Abuse Intramural Research Program.

Each rat was anesthetized with a mixture of ketamine $\mathrm{HCl}(80 \mathrm{mg} / \mathrm{kg}$, i.m.) and xylazine (10 mg/kg, i.m.) and mounted in a stereotaxic apparatus. Holes were drilled through the skull over two areas of interest: the NAcc (antero-posterior, $1.2 \mathrm{~mm}$; lateral, $0.9 \mathrm{~mm}$ ) and the hippocampus (antero-posterior, $-3.5 \mathrm{~mm}$; lateral, $2.0 \mathrm{~mm}$ ). The dura matter was carefully retracted, and each temperature probe was slowly lowered to the intended target area (7.2 and $4.0 \mathrm{~mm}$ for the NAcc and hippocampus, respectively). A third temperature probe was implanted in deep temporal muscle. The probes were secured with dental cement to three stainlesssteel screws threaded into the skull. Experimentation began after a $3 \mathrm{~d}$ recovery period and continued for the next six daily sessions.

Temperature probes and recording instruments. The thermocouple probes were prepared from copper and constantin wires (TW-35P; diameter, $\sim 125 \mu \mathrm{m}$ ) obtained from Physitemp Instruments (Clifton, NJ). After mechanically removing the insulation $200-400 \mu \mathrm{m}$ from the tip of each wire, the tips were welded together and reinsulated with polyester microshrink tubing and epoxy. The wires were connected to copper and constantin pins and fixed in a plastic connector with epoxy. During experiments, the probes were connected to the recording instrument (Thermes-16; Physitemp Instruments) via individual sockets, a common cord, and a nine channel electric swivel commutator.

During the session, temperatures were continuously recorded and stored in computer memory at $10 \mathrm{sec}$ intervals. The temperature in the room was maintained automatically at $23^{\circ} \mathrm{C}$, and the stability of the temperature in the chamber throughout the sessions (fluctuations between 23 and $24^{\circ} \mathrm{C}$ ) was confirmed by an additional thermosensor.

Experimental protocol. All recordings took place during the light phase of the animal's cycle (8:00 A.M. to 8:00 P.M.) in an electrically shielded Plexiglas chamber $(35 \times 35 \times 40 \mathrm{~cm})$. Each day, the rats were brought from their housing facility, placed in the chamber, connected to the recording instrument, and allowed to habituate to the experimental environment. During habituation, the rats engaged in locomotion, grooming, and rearing that was accompanied by increases in both brain and body temperature (Kiyatkin and Wise, 2001). After $1 \mathrm{~d}$ of habituation to the test environment, regular testing began. On day 2, after 90-120 min of habituation, during which behavior and temperature stabilized at low levels, an ovariectomized female rat was placed in the same cage as onehalf of the rats ( $n=6$; randomly assigned). The female was presented when the rat was in quiet resting or sleep-like conditions with no overt movements. After $30 \mathrm{~min}$, all rats were injected subcutaneously with the daily concentration of $\operatorname{METH}(0,1,3,9$, and $0 \mathrm{mg} / \mathrm{kg}$ for the $5 \mathrm{~d}$, based on weight at the time of surgery). Ninety minutes after injection, females were removed from the cages. Recording continued for an additional 5-6 hr. To minimize between-group variability, rats were paired (injection with and without female interaction) to be of similar weight and were tested simultaneously.

Histology. After completion of the experiments, each rat was deeply anesthetized and decapitated; brains were removed and stored in $10 \%$ formalin solution for subsequent histological processing. The location of the recording sites was determined from cryostat-cut, $30 \mu \mathrm{m}$ slices mounted on glass slides.

Data analysis. The significance of temperature differences was evaluated using ANOVA with repeated measures followed by Fisher tests comparing $10 \mathrm{~min}$ intervals. The data were presented as changes in absolute temperature, changes relative to the pre-event baseline, and temperature differences between recording sites. Because the generative source of hyperthermia within brain and body can vary, the latter parameter (i.e., brain site-muscle difference relative to the point immediately preceding the injection) was instructive in determining the source of the hyperthermic response (Kiyatkin and Wise, 2001). Unpaired $t$ tests were used to compare the durations of hyperthermia between groups.

\section{Results}

Data were obtained in 12 male rats (59 sessions) that had thermocouple probes located in the intended target areas and artifact-free recordings in each of three sites.

\section{Methamphetamine effects under quiet resting conditions}

Figure 1 shows mean changes in temperature in each recording location after drug administration under quiet resting conditions. Under these conditions, saline injection by itself induced movement activation as well as a significant and generally correlated temperature increase $\left(\sim 0.5^{\circ} \mathrm{C}\right)$ in all recording sites. $\mathrm{Al}-$ though movement activation was visually evident for a few minutes after the injection, the temperature increase was more prolonged ( $\sim 30 \mathrm{~min}$ ), peaking at $\sim 15 \mathrm{~min}$. The temperature increase was more rapid in both brain sites (especially in the NAcc) than in the muscle, resulting in the appearance of a transient but significant increase in the brain-muscle differential.

METH injection induced dose-dependent hyperthermia. Compared with transient temperature elevation after saline injection, METH at the lowest dose $(1 \mathrm{mg} / \mathrm{kg})$ induced a larger $\left(\sim 1^{\circ} \mathrm{C}\right)$ and much longer (135-145 min depending on area) elevation, which was more rapid and stronger in both brain structures than in the muscle (Fig. $1 B$ ). Because of this dynamic, the brain-muscle temperature differential (Fig. 1C) rapidly increased after drug injection and remained elevated for 50 (hippocampus) or 110 (NAcc) min. A similar pattern was observed after METH at the moderate dose $(3 \mathrm{mg} / \mathrm{kg})$, with a mean temperature elevation of $\sim 1.3^{\circ} \mathrm{C}$ and a duration of $205-215 \mathrm{~min}$. The strongest response occurred at the highest dose $(9 \mathrm{mg} / \mathrm{kg})$, with a mean elevation of $\sim 3.5^{\circ} \mathrm{C}$ and a duration longer than the entire period of postinjection recording ( $>315 \mathrm{~min}$ ). Similar to other situations, brain temperature increase in this case was more rapid and stronger than in the muscle, and the change in brain-muscle differential was exceptionally strong and prolonged (Fig. 1C). The temperature difference between the NAcc and muscle rapidly increased for the first 10 min after drug administration, peaked at $40-50 \mathrm{~min}\left(\sim 0.5^{\circ} \mathrm{C}\right)$, and maintained an increased level for the entire period of observation. Similar but smaller changes were seen for the hippocampus-muscle difference. A saline injection during the fifth daily session produced no significant change in temperature.

Consistent with our previous observations (Kiyatkin et al., 2002), basal temperatures in the NAcc in the present study (Fig. $1 A$ ) were significantly higher than in the hippocampus, whereas muscle had intermediate values. These between-site differences were consistent in all animals both within and between sessions.

\section{Methamphetamine effects during social interaction}

Introduction of a female conspecific led to consistent behavioral activation and significant hyperthermia (Fig. 2). The amplitude of temperature elevation was relatively stable over repeated sessions $\left(\sim 1.3,1.7,1.5,1.5\right.$, and $1.2^{\circ} \mathrm{C}$ respective to each day). In general, temperature elevation in all areas reached a plateau 15-25 min after the start of social interaction (Fig. 2B), the temperature acceleration was maximal during the first $10 \mathrm{~min}$, and absolute temperature declined during the subsequent $40-50$ min. Saline injection during social interaction had no effect on temperatures, which slowly decreased, reaching baseline values at 100-110 min (i.e., 10-20 min before the female was removed from the cage). The removal of the female resulted in a transient temperature increase that did not reach the level of statistical significance. In contrast to the control injections, METH injections significantly modified the thermal response associated with social interaction, and METH-induced temperature increases under these conditions were significantly stronger and longer than that under quiet resting conditions. The mean peak values of NAcc temperature after METH were, for example, 38.06 (range, $37.55-38.74$ ), 38.30 (range, 38.05-39.33), and $40.27^{\circ}$ (range, 
Saline-1
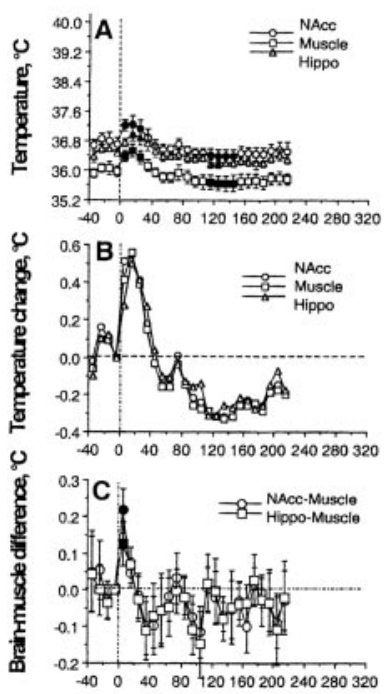

Trme, min
$1 \mathrm{mg} / \mathrm{kg}$
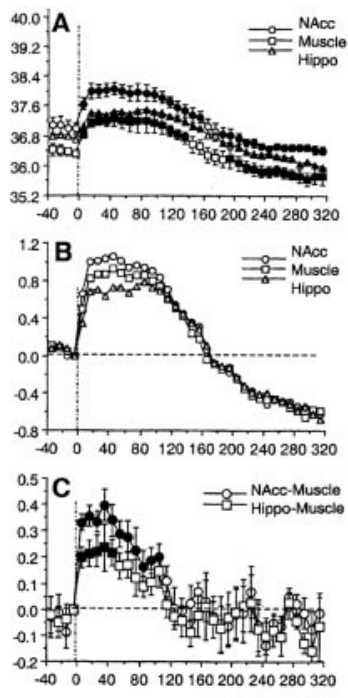

Trme, $\min$
$3 \mathrm{mg} / \mathrm{kg}$
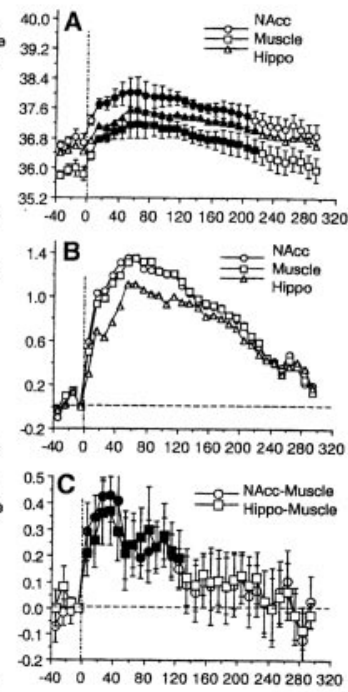

Trme, min
$9 \mathrm{mg} / \mathrm{kg}$
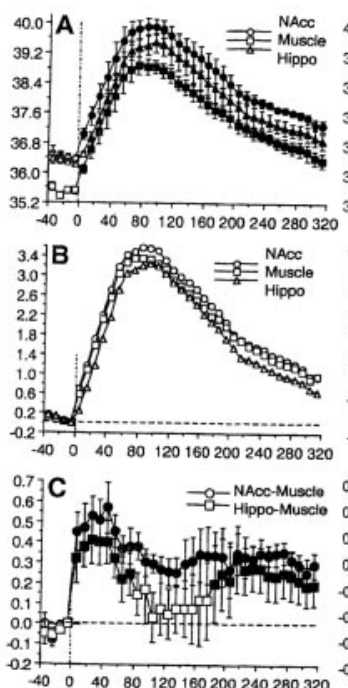

Trme, min
Saline-2
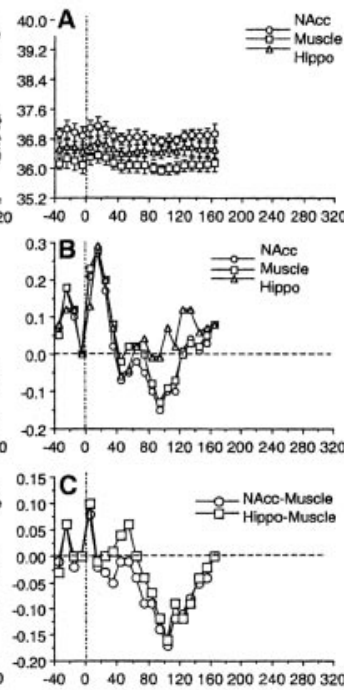

Trme, min

Figure 1. Mean changes in brain and muscle temperature after subcutaneous administration of methamphetamine at low, moderate, and high doses as well as after two control injections of saline. Absolute temperatures $(A)$, temperature changes normalized with respect to the moment of injection $(B)$, and relative brain-muscle difference (i.e., differences in temperature dynamics in different recording sites with the preinjection baseline set as zero) ( $C$ ) are shown. Both absolute temperature changes and brain-muscle difference were analyzed for each set of data with one-way ANOVA with repeated measures; filled symbols show values significantly different (Fisher test) from preinjection baseline. Values of ANOVA for temperature elevation are as follows: saline injection 1 (Saline-1): $F_{(22,137)}=6.30,4.73,6.10$ for the NAcc, muscle, and hippocampus (Hippo), respectively, and $p<0.01$ for each case; $1 \mathrm{mg} / \mathrm{kg} \mathrm{METH:} F_{(28,173)}=34.90,26.71,23.73$ and $p<0.001$ for each case; $3 \mathrm{mg} / \mathrm{kg} \mathrm{METH:} F_{(28,173)}=2.34,2.854,2.02$ and $p<0.05$ for each case; $9 \mathrm{mg} / \mathrm{kg} \mathrm{METH}: F_{(30,185)}=17.73,18.84,17.29$ and $p<0.001$ for each case. Values of ANOVA for NAcc-muscle and hippocampus-muscle difference are as follows: saline injection 1 (Saline-1): $F_{(22,137)}=3.12,2.34$ and $p<0.05$ for each case; $1 \mathrm{mg} / \mathrm{kg}$ METH: $F_{(28,173)}=7.55,2.83$ and $p<0.01$ for each case; $3 \mathrm{mg} / \mathrm{kg} \mathrm{METH}: F_{(28,173)}=3.60,3.56$ and $p<0.05$ for both cases; $9 \mathrm{mg} / \mathrm{kg} \mathrm{METH:} F_{(30,185)}=17.73,17.22$ and $p<0.001$ for each case. The effects of time for saline 2 (Saline-2) were nonsignificant in both cases $(p>0.1)$.

$39.63-41.52)$ at 1,3 , and $9 \mathrm{mg} / \mathrm{kg}$, respectively, whereas the durations of significant elevation were 165,205 , and $>345 \mathrm{~min}$. Similar increases in the magnitude and durations of METHinduced temperature were evident in all other recording sites. The second saline session revealed a pattern similar to the first saline session.

The mean brain-body temperature difference (Fig. 2C) rapidly increased after placement of the female, but the degree of this change decreased across repeated sessions. After an injection of $\mathrm{METH}$, the temperature difference increased for all three doses, again varying by structure. At 1 and $3 \mathrm{mg} / \mathrm{kg}$, the difference was significant for $\sim 65 \mathrm{~min}$, and at $9 \mathrm{mg} / \mathrm{kg}$, it remained elevated, and especially strong for the NAcc, for the entire postinjection period. Brain-body difference did not increase after either saline injection.

Because previous work has shown fluctuations of up to $2^{\circ} \mathrm{C}$ to be within normal physiological function (Kiyatkin and Wise, 2001; Kiyatkin et al., 2002), time spent above this limit can be considered a measure of the duration of abnormal hyperthermia. Mean temperature at quiet resting conditions (i.e., time before injection or introduction of the female) was determined to be $36.72,35.93$, and $36.39^{\circ} \mathrm{C}(n=59$ for each case) for the NAcc, hippocampus, and muscle, respectively. Time spent $2^{\circ} \mathrm{C}$ above these levels is shown in Figure 3. For each recording site, temperature after $9 \mathrm{mg} / \mathrm{kg}$ METH remained elevated longer in the rats that experienced social interaction, although this effect was significant only for the NAcc and hippocampus.

Although both the magnitudes and durations of METHinduced temperature elevations were higher when the drug was used during social interaction, in two of six animals, METHinduced hyperthermia at $9 \mathrm{mg} / \mathrm{kg}$ was especially robust and clearly pathological, with NAcc temperatures exceeding $41^{\circ} \mathrm{C}$. These two animals also showed atypically strong and long-term stereotypy and other signs of excessive autonomic activation (i.e., urination), and one of the rats died after the session. Although, between-animal variability was also high when $\mathrm{METH}$ was given under control conditions, NAcc temperature peaks of $>40^{\circ} \mathrm{C}$ were seen only in two animals. Figure 4 shows an example of such pathological responding. Although the two rats had almost identical body weight and were recorded simultaneously in the same environment, in the first case NAcc temperature peaked at $39.58^{\circ} \mathrm{C}$, whereas in the second case NAcc temperature was elevated above $40^{\circ} \mathrm{C}$ for $192 \mathrm{~min}$. There were also striking betweenanimal differences in the brain-muscle dynamic. When METH was injected under quiet resting conditions, NAcc- and hippocampus-muscle differences were increased for $\sim 3 \mathrm{hr}$, but when the drug was administered during social interaction, these differences remained abnormally elevated for $>6 \mathrm{hr}$.

\section{Discussion}

The present study revealed two new findings about METHinduced hyperthermia. First, METH induces dose-dependent brain hyperthermia that precedes and is greater than overall body hyperthermia, suggesting METH-induced neuronal activation as a contributing source of that hyperthermia. Second, the hyperthermia induced by METH is potentiated in animals already hyperthermic from social interaction. These findings raise the possibility that the use of METH and related compounds in social or otherwise arousing situations increases the risk for adverse effects inherent to these drugs. 
Saline-1
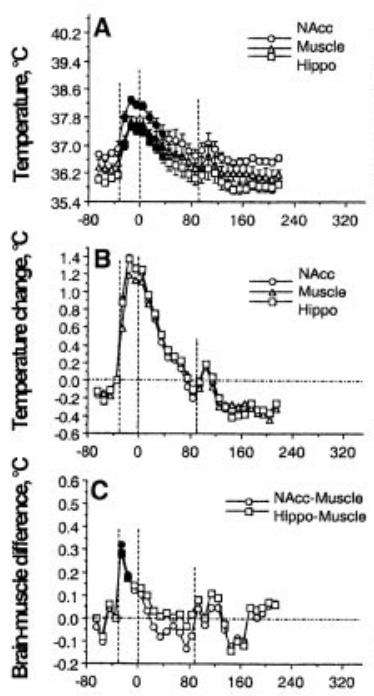

Trme, min
$1 \mathrm{mg} / \mathrm{kg}$
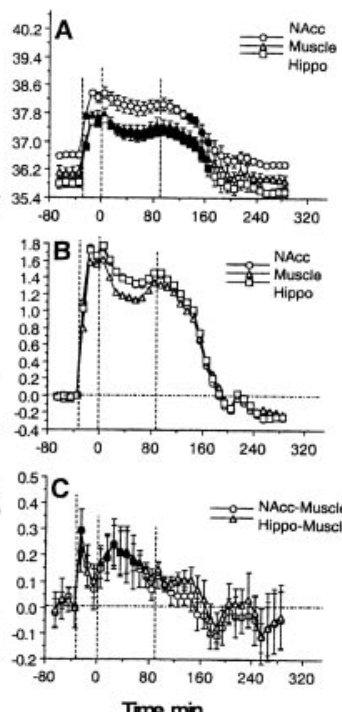

$3 \mathrm{mg} / \mathrm{kg}$
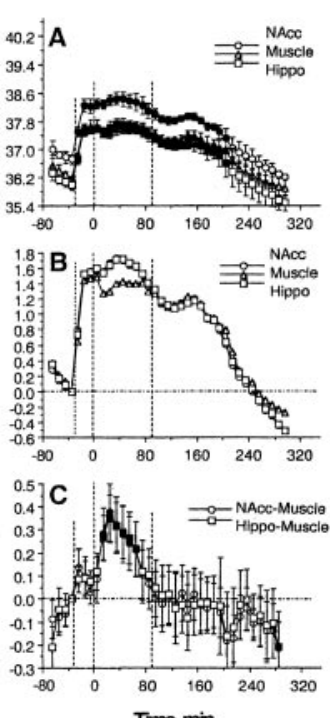

$9 \mathrm{mg} / \mathrm{kg}$
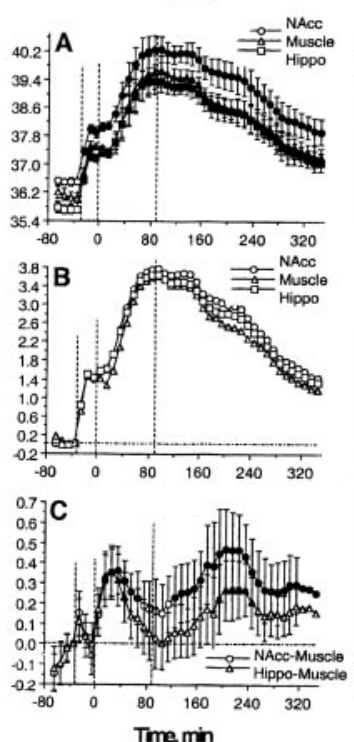

Saline-2
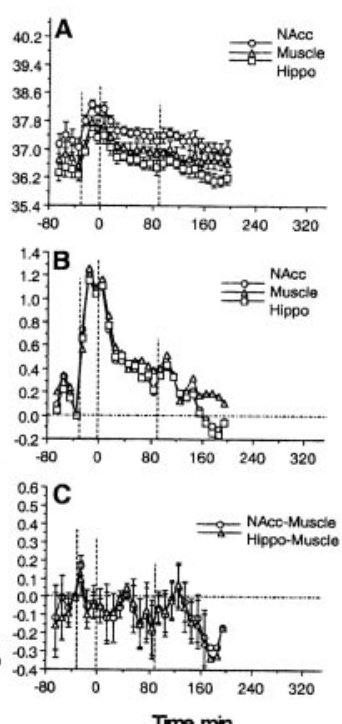

Figure 2. Mean changes in brain and muscle temperature after subcutaneous administration of methamphetamine at low, moderate, and high doses as well as after two control injections of saline during social interaction. The first and third vertical hatched lines in each graph show the moments when the female was placed and removed from the cage, and the second vertical line shows the moment of subcutaneous injection. The format is the same as described for Figure 1. ANOVA values for temperature elevation are as follows: for Saline-1, $F_{(25,155)}=18.47,17.04,20.11$, respectively, for the NAcc, muscle, and hippocampus (Hippo); for $1 \mathrm{mg} / \mathrm{kg} \mathrm{METH}, F_{(32,197)}=35.47,36.51,38.25 ;$ for $3 \mathrm{mg} / \mathrm{kg} \mathrm{METH,} F_{(33,203)}=17.22,14.39,15.98 ;$ for $9 \mathrm{mg} / \mathrm{kg} \mathrm{METH,} F_{(39,239)}=$ $14.99,15.18,16.07$; for Saline-2, $F_{(23,119)}=4.28,3.58,4.51$ (all $p<0.05$; Fisher test). The increase in brain-body temperature difference for the first 30 min of social interaction was significant for the first saline injection $\left(F_{(25,155)}=2.25,1.96\right.$, respectively, for NAcc-muscle and hippocampus-muscle; $\left.p<0.05\right), 1 \mathrm{mg} / \mathrm{kg} \mathrm{METH}\left(F_{(32,197)}=3.73,3.46 ; p<0.05\right)$, and the second saline injection $\left(F_{(23,119)}=3.58,4.51 ; p<0.05\right)$. The increase after injection was absent in both saline cases but was significant after METH at all three doses $\left(1 \mathrm{mg} / \mathrm{kg}: F_{(32,197)}=3.73,3.46, p<0.05\right.$; $3 \mathrm{mg} / \mathrm{kg}: F_{(32,197)}=5.24,3.62 ;$ all $p$ values $\left.<0.05 ; 9 \mathrm{mg} / \mathrm{kg}: F_{(35,215)}=2.45,1.91, p<0.05\right)$.

\section{METH induces pathological metabolic neural activation and hyperthermia}

Our finding that METH induces dose-dependent hyperthermia that develops consistently faster and is greater in brain structures than in the head muscle suggests neural activation as a source of brain hyperthermia and as the primary force behind subsequent body hyperthermia. Although sympathetic activation may be a major contributor to body hyperthermia, this activation is centrally determined. Increased body temperature, therefore, is a consequence of the central action of the drug rather than a secondary consequence of movement activation or some other action in the periphery. METH-induced hyperthermia was structure-specific (stronger and longer lasting in the NAcc than in hippocampus). It was more robust and sustained than hyperthermia seen under a variety of behavioral conditions in the absence of drug (Kiyatkin and Wise, 2001) (social interaction in the present study). Excessive and prolonged heat production induced by METH at the highest dose was especially evident in the brain-muscle temperature differential. The differential between the NAcc and muscle after $9 \mathrm{mg} / \mathrm{kg}$ METH rapidly increased to $\sim 0.5^{\circ} \mathrm{C}$ and was maintained above normal physiological levels $\left(0.3-0.4^{\circ} \mathrm{C}\right)$ for $>5 \mathrm{hr}$. Because heat is continuously removed from brain tissue by circulating blood, and because the lungs cool the blood just before it enters the brain, the strength of the brainmuscle difference induced by the drug gives evidence of the strength of the drug-induced neural activation.

Change in brain temperature is a factor that affects various neural functions ranging from the activity of ionic channels and receptor sensitivity (Thompson et al., 1985; Rosen, 2001) to such global neuronal alterations as release and uptake of neurotransmitters (Andersen and Moser, 1995; Xie et al., 2000). Thus, the $\mathrm{METH}$-induced metabolic activation suggested by our tempera- ture measurements could be a "common denominator" for various abnormalities in neural functions (i.e., thermal stress, oxidative stress, abnormal transmitter release, decrease in ATP, etc.) that are suggested as factors determining acute and chronic adverse effects of this drug, including neurotoxicity (Alberts and Sonsalla, 1995; Ali et al., 1996; Clausing and Bowyer, 1999). In some animals, NAcc elevation exceeded $41^{\circ} \mathrm{C}\left(5^{\circ} \mathrm{C}\right.$ above resting baseline), a temperature associated with irreversible damage of mitochondrial and plasma membranes and cellular organelles (Lepock et al., 1983; Iwagami, 1996; Willis et al., 2000). Thus the degree of METH-induced hyperthermia under conditions of social arousal may have toxic consequences above and beyond the

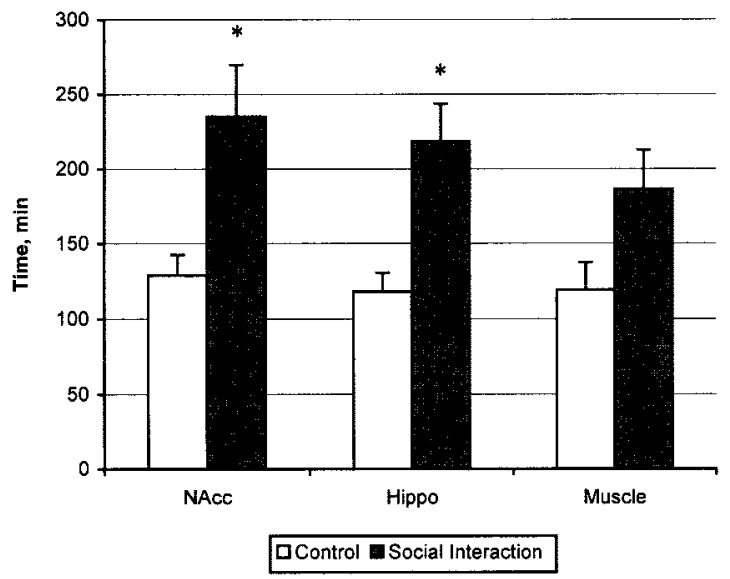

Figure 3. Mean \pm SEM time spent $2^{\circ}$ above baseline temperatures, compared by group at 9 $\mathrm{mg} / \mathrm{kg}$. $t$ values were $t_{10}=2.851\left({ }^{*} p<0.05\right), 3.548\left({ }^{*} p<0.01\right)$, and 2.134 ( $\left.p=0.0596\right)$ for the NAcc, hippocampus (Hippo), and muscle, respectively (unpaired Student's $t$ test). 

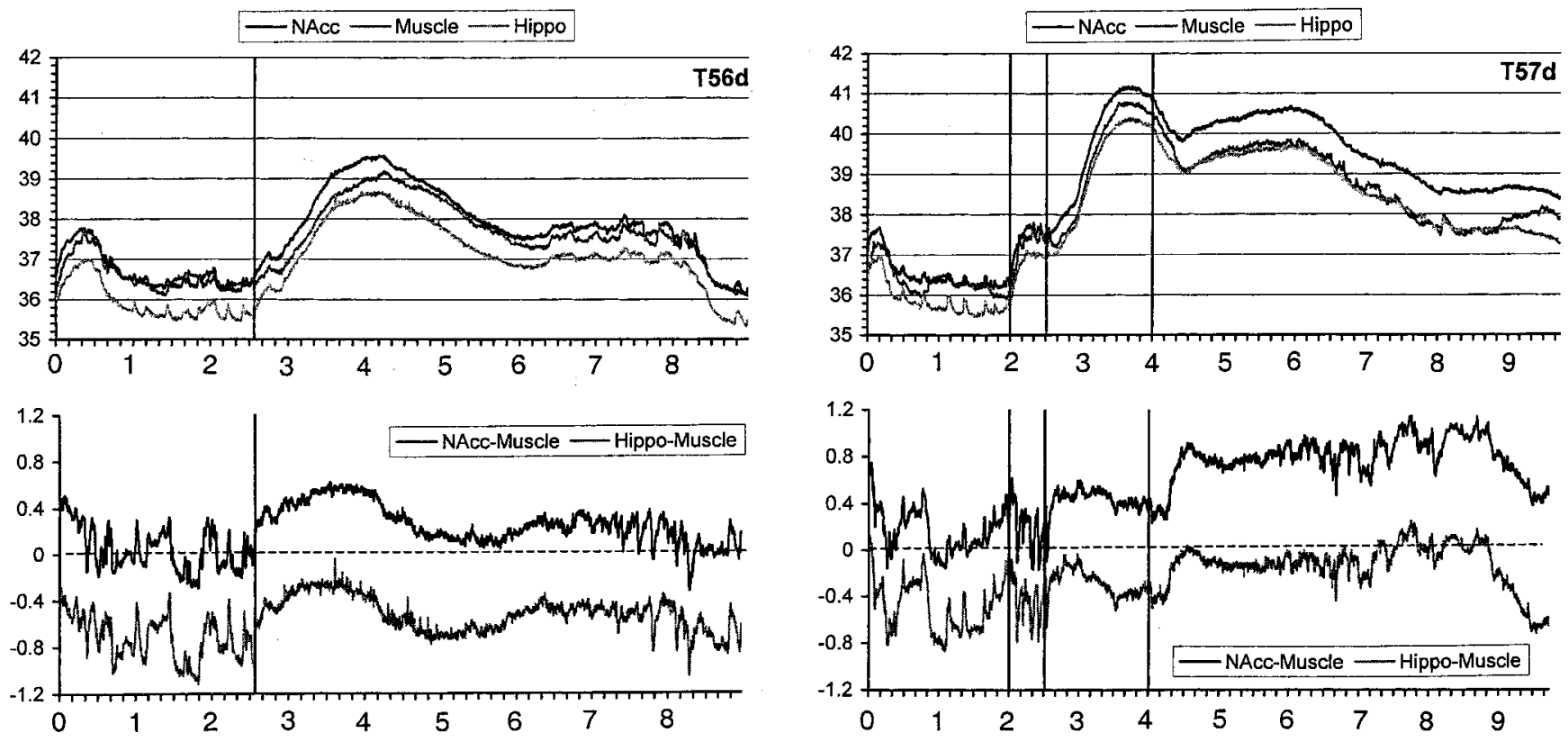

Figure 4. Two original records of temperature dynamics after METH administration to rats under quiet resting conditions (left) and during social interaction (right). Top graphs show absolute temperatures in each recording location, and bottom graphs depict changes in NAcc- and hippocampus (Hippo)-muscle difference.

temperature-sensitive toxicity of monoamine terminals (Bowyer et al., 1993, 1994).

High-activity state exacerbates METH-induced hyperthermia The hyperthermic effect of METH was significantly potentiated by social interaction, with clearly pathological overheating in all animals and one animal fatality at the highest drug dose. Although the effects were not additive, the magnitude of METHinduced hyperthermia during social interaction increased $\sim 0.5^{\circ} \mathrm{C}$, and higher temperatures were maintained for significantly longer times. It is known that both toxicity and mortality induced by METH and its analogs are powerfully increased in mice by social crowding and aggregation (Shintomi, 1975; Blackshear et al., 1979; Vargas-Rivera et al., 1990). Although crowding itself may cause hyperthermia by restricting the airflow essential for radiant cooling, this factor was unlikely to have contributed to the hyperthermia seen during social interaction. First, we used only two animals, which interacted in a large cage and did not huddle together. Second, the air temperature in the cage did not increase during the period of social interaction. Third, the maximum brain temperature increase was seen in the first $10 \mathrm{~min}$ of social interaction, too early for significant accumulation of body heat. Perhaps the most significant evidence against overheating from aggregation was that the temperature increases during these social interactions were always more rapid and stronger in the brain than in the muscle. This suggests that neural activation within the male animal, and not heat transfer from body contact with the female, was the source of the brain hyperthermia we observed.

The present experiments underscore the importance of set (the current brain state) and setting (the environment and its impinging stimuli) in determining the effectiveness of drugs for a given action in a given situation. This is particularly important with respect to the toxic effects of stimulant drugs such as METH. These effects are temperature dependent (Bowyer et al., 1993, 1994; Miller and O'Callaghan, 1994; Alberts and Sonsalla, 1995; Farfel and Seiden, 1995; Ali et al., 1996; Davidson et al., 2001), and a wide range of conditions can influence brain as well as core temperature. In the present case, administration of the drug at 9 $\mathrm{mg} / \mathrm{kg}$ during a social interaction was often sufficient to bring brain temperature close to its biological limit, resulting in the death of one of our animals. Although humans use METH and related substances at much lower doses, some individuals repeatedly administer METH intravenously, and this route of administration is more likely to lead to death (Kalant and Kalant, 1975). In addition, intake of the drug usually occurs during high-activity social situations, which are accompanied by a stronger neural activation and a presumably more profound hyperthermia than that seen during modest social interaction in our experiments. These drug intakes are frequently associated with dancing and sexual interactions (Rawson et al., 2002), which strongly contribute to overall hyperthermia through cardiac and striatal muscle exertion, and with loud music, which is known to potentiate gliolysis in mice (Morton et al., 2001). Whether these activities would exacerbate METH-induced hyperthermia in a manner similar to the interaction with a nonreceptive female in the present study remains to be explored.

\section{References}

Alberts DS, Sonsalla PK (1995) Methamphetamine-induced hyperthermia and dopaminergic neurotoxicity in mice: pharmacological profile of protective and nonprotective agents. J Pharmacol Exp Ther 275:1104-1114.

Ali SF, Newport GD, Slikker W (1996) Methamphetamine-induced dopaminergic toxicity in mice: role of environmental temperature and pharmacological agents. Ann NY Acad Sci 801:187-198.

Andersen P, Moser EI (1995) Brain temperature and hippocampal function. Hippocampus 5:491-498.

Blackshear MA, Wade LH, Proctor CD (1979) Effects of crowding on amphetamine-induced disaggregation of brain polyribosomes. Arch Int Pharmacodyn Ther 241:180-189.

Bowyer JF, Gough B, Slikker Jr W, Lipe GW, Newport GD, Holson RR (1993) Effects of a cold environment or age on methamphetamine-induced dopamine release in the caudate putamen of female rats. Pharmacol Biochem Behav 44:87-98.

Bowyer JF, Davies DL, Schmued L, Broening HW, Newport GD, Slikker Jr W, 
Holson RR (1994) Further studies of the role of hyperthermia in methamphetamine neurotoxicity. J Pharmacol Exp Ther 268:1571-1580.

Cadet JL, Thiriet N, Jayanthi S (2001) Involvement of free radicals in MDMA-induced neurotoxicity in mice. Ann Med Intern 152 [Suppl 3]:IS57-IS59.

Clausing P, Bowyer JK (1999) Time course of brain temperature and caudate/putamen microdialysis levels of amphetamine and dopamine in rats after multiple doses of $d$-amphetamine. Ann NY Acad Sci 890:495-504.

Davidson C, Gow AJ, Lee TH, Ellinwood EH (2001) Methamphetamine neurotoxicity: necrotic and apoptotic mechanisms and relevance to human abuse and treatment. Brain Res Brain Res Rev 36:1-22.

Farfel GM, Seiden LS (1995) Role of hypothermia in the mechanisms of protection against serotonergic toxicity. II. Experiments with methamphetamine, $p$-chloroamphetamine, fenfluramine, dizocipline, and dextromethorphan. J Pharmacol Exp Ther 272:868-875.

Iwagami Y (1996) Changes in the ultrastructure of human cell related to certain biological responses under hyperthermic culture conditions. Human Cell 9:353-366.

Kalant H (2001) The pharmacology and toxicology of "ecstasy" (MDMA) and related drugs. Can Med Assoc J 165:917-928.

Kalant H, Kalant OJ (1975) Death in amphetamine users: causes and rates. Can Med Assoc J 112:299-304.

Kiyatkin EA, Wise RA (2001) Striatal hyperthermia associated with arousal: intracranial thermorecordings in behaving rats. Brain Res 918:141-152.

Kiyatkin EA, Brown PL, Wise RA (2002) Brain temperature fluctuation: a reflection of functional neural activation. Eur J Neurosci 17:1-5.

Kuhn DM, Geddes TJ (2000) Molecular footprints of neurotoxic amphetamine action. Ann NY Acad Sci 914:92-103.

Lepock JR, Cheng K-H, Al-Qysi H, Kruuv J (1983) Thermotropic lipid and protein transitions in Chinese hamster lung cell membranes: relationship to hyperthermic cell killing. Can J Biochem Cell Biol 61:421-427.

Lin PS, Quamo S, Ho KC, Gladding J (1991) Hyperthermia enhances the cytotoxic effects of reactive oxygen species to Chinese hamster cells and bovine endothelial cells in vitro. Radiat Res 126:43-51.

Lipton SA, Rosenberg PA (1994) Excitatory amino acids as a final common pathway for neurologic disorders. N Engl J Med 330:613-622.

Miller DB, O'Callaghan JP (1994) Environment-, drug- and stress-induced alterations in body temperature affect the neurotoxicity of substituted amphetamines in the C57BL/6J mouse. J Pharmacol Exp Ther 270:752-760.
Morton AJ, Hickey MA, Dean LC (2001) Methamphetamine toxicity in mice is potentiated by exposure to loud music. NeuroReport 12:3277-3281.

Ohmori T, Abekawa T, Koyama T (1996) The role of glutamate in behavioral and neurotoxic effects of methamphetamine. Neurochem Int 29:301-307.

Omar RA, Yano S, Kikkawa Y (1987) Antioxidant enzymes and survival of normal and simian virus 40-transformed mouse embryo cells after hyperthermia. Cancer Res 47:3473-3476.

Rawson RA, Anglin MD, Ling W (2002) Will the methamphetamine problem go away? J Addictive Diseases 21:5-19.

Rosen AD (2001) Nonlinear temperature modulation of sodium channel kinetics in GH3 cells. Biochim Biophys Acta 1511:391-396.

Sandoval V, Hanson GR, Fleckenstein AE (2000) Methamphetamine decreases mouse striatal dopamine transporter activity: roles of hyperthermia and dopamine. Eur J Pharmacol 409:265-271.

Seiden LS, Sabol KE (1996) Methamphetamine and methylenedioxymethamphetamine neurotoxicity: possible mechanisms of cell destruction. NIDA Res Monogr 163:251-276.

Shintomi K (1975) Effects of psychotropic drugs on methamphetamineinduced behavioral excitation in grouped mice. Eur J Pharmacol 31:195-206.

Spina MB, Cohen G (1989) Dopamine turnover and glutathione oxidation: implications for Parkinson disease. Proc Natl Acad Sci USA 86:1398-1400.

Stephens SE, Yamamoto BK (1994) Methamphetamine-induced neurotoxicity: roles for glutamate and dopamine efflux. Synapse 17:203-209.

Thompson SM, Musakawa LM, Rince DA（1985） Temperature dependence of intrinsic membrane properties and synaptic potentials in hippocampal CA1 neurons in vitro. J Neurosci 5:817-824.

Vargas-Rivera J, Ortega-Corona BG, Garcia-Pineda J, Carranza J, Salazar LA, Villarreal J (1990) Influence of previous housing history on the toxicity of amphetamine in aggregate mice. Arch Invest Med 21:65-69.

Willis WT, Jackman MR, Bizeau ME, Pagliassotti MJ, Hazel JR (2000) Hyperthermia impairs liver mitochondrial functions. Am J Physiol 278:R1240-R1246.

Xie T, McGann UD, Kim S, Yuan J, Ricaurte GA (2000) Effect of temperature on dopamine transporter function and intracellular accumulation of methamphetamine: implications for methamphetamine-induced dopaminergic neurotoxicity. J Neurosci 20:7838-7845. 